\title{
RNA-DNA sequence differences in Saccharomyces cerevisiae
}

\author{
Isabel X. Wang, ${ }^{1}$ Christopher Grunseich, ${ }^{2}$ Youree G. Chung, ${ }^{3}$ Hojoong Kwak, ${ }^{1,4}$ \\ Girish Ramrattan, ${ }^{1,4}$ Zhengwei Zhu, ${ }^{1}$ and Vivian G. Cheung ${ }^{1,4,5}$ \\ ${ }^{1}$ Life Sciences Institute, University of Michigan, Ann Arbor, Michigan 48109, USA; ${ }^{2}$ Neurogenetics Branch, National Institute \\ of Neurological Disorders and Stroke, National Institutes of Health, Bethesda, Maryland 20892, USA; ${ }^{3}$ College of Engineering, \\ University of Michigan, Ann Arbor, Michigan 48109, USA; ${ }^{4}$ Howard Hughes Medical Institute, Chevy Chase, Maryland 20815, USA; \\ ${ }^{5}$ Departments of Pediatrics and Genetics, University of Michigan, Ann Arbor, Michigan 48109, USA
}

\begin{abstract}
Alterations of RNA sequences and structures, such as those from editing and alternative splicing, result in two or more RNA transcripts from a DNA template. It was thought that in yeast, RNA editing only occurs in tRNAs. Here, we found that Saccharomyces cerevisiae have all 12 types of RNA-DNA sequence differences (RDDs) in the mRNA. We showed these sequence differences are propagated to proteins, as we identified peptides encoded by the RNA sequences in addition to those by the DNA sequences at RDD sites. RDDs are significantly enriched at regions with R-loops. A screen of yeast mutants showed that RDD formation is affected by mutations in genes regulating R-loops. Loss-of-function mutations in ribonuclease $\mathrm{H}$, senataxin, and topoisomerase I that resolve RNA-DNA hybrids lead to increases in RDD frequency. Our results demonstrate that RDD is a conserved process that diversifies transcriptomes and proteomes and provide a mechanistic link between R-loops and RDDs.
\end{abstract}

[Supplemental material is available for this article.]

DNA is the genetic blueprint that provides the code for synthesizing RNA and proteins; however, there is not always a direct one-to-one relationship between DNA, RNA, and protein. Cotranscriptional and post-transcriptional processing such as splicing and RNA editing alters the sequences and structures of RNA. As a result, different transcripts are produced from the same DNA sequences.

RNA editing was first identified in the mitochondrial genome of kinetoplastids (Benne et al. 1986). Subsequently, different types of RNA editing were found in the mitochondrial and nuclear genomes of diverse organisms including plants (Gualberto et al. 1989; Hiesel et al. 1989), viruses (Volchkov et al. 2001), mollusks (Garrett and Rosenthal 2012; Albertin et al. 2015), and human (Tennyson et al. 1989; Teng et al. 1993). The mechanisms that mediate these events and the functions of the edited transcripts are mostly unknown. However, as sequencing technology improves, information about RNA editing is accumulating. Adenosine-toinosine editing mediated by the human adenosine deaminases acting on RNA (ADAR) proteins was once regarded as rare events. Recently, hundreds of thousands of ADAR-mediated editing sites have been identified in human cells (Kawahara et al. 2004; Ju et al. 2011; Alon et al. 2012; Chen et al. 2012; Peng et al. 2012; Silberberg et al. 2012; Vesely et al. 2012; Chen 2013; Wang et al. 2013; Bazak et al. 2014). Furthermore, we and others have found that there are other types of RNA-DNA sequence differences (RDDs) that are unlikely to be mediated by these deaminases ( $\mathrm{Li}$ et al. 2011; Bahn et al. 2012; Bar-Yaacov et al. 2013; Rubio et al. 2013; Turner et al. 2015). These events are found in normal cells,

Corresponding authors: ixwang@umich.edu, vgcheung@umich.edu Article published online before print. Article, supplemental material, and publication date are at http://www.genome.org/cgi/doi/10.1101/gr.207878.116. Freely available online through the Genome Research Open Access option. and altered patterns of RDDs were found in neurologic diseases (van Leeuwen et al. 1998; Silberberg et al. 2012; Krestel et al. 2013; Wang et al. 2014) and in cancers (Klimek-Tomczak et al. 2006; Martinez et al. 2008; Lee et al. 2013; Avesson and Barry 2014; Han et al. 2014; Niavarani et al. 2015). Although differences between RNA and their corresponding DNA templates were known for many years, their discoveries in human beyond the editing events mediated by ADAR and APOBEC families of deaminases were debated. Some groups posited that the RDDs are not as widespread as reported, and/or they are the results of inaccurate sequencing and/or analyses of deep sequencing data (Kleinman and Majewski 2012; Lin et al. 2012; Pickrell et al. 2012). We have addressed many of these concerns (Li et al. 2012), and other groups have identified RDDs in human cells. The first published work we know of is a G-to-A site in WT1, Wilms tumor 1 (Sharma et al. 1994). Subsequently RDD sites in brain tissues from Alzheimer's and Down syndrome patients (van Leeuwen et al. 1998) and in other human cells were identified (Ju et al. 2011; Bahn et al. 2012; Silberberg et al. 2012; Turner et al. 2015; Zhang et al. 2015). A recent paper suggests that APOBEC3A is the protein that mediates G-to-A RDD in WT1 (Niavarani et al. 2015).

Despite advances in technologies for sequencing and analysis of RNA transcripts, it is still challenging to survey enough human cells comprehensively, especially for those RDDs that are present at lower frequencies. To obtain such a comprehensive view, we studied the DNA and RNA of budding yeast Saccharomyces cerevisiae, and here we present data from 18 yeast strains, including wild-type and mutants. national), as described at http://creativecommons.org/licenses/by-nc/4.0/. 


\section{Results}

\section{RDDs in wild-type yeast strains}

We sequenced the DNA and RNA of six wild-type budding yeast strains commonly used in research laboratories, including S288C, the reference strain of the yeast genome project (Engel et al. 2013). For each strain, we obtained about 40 million DNA-seq reads (greater than 250× genome coverage) and sequenced the transcriptomes to an average of 10 million 100 -nt reads. To identify RDDs for each yeast strain, we compared the RNA sequences to the corresponding DNA sequences (Methods; Supplemental Results; Supplemental Fig. S1). We found in S288C more than 750 RDD sites, corresponding to a frequency of $1.5 \mathrm{RDD}$ per 10,000 nucleotides in the transcriptome (Supplemental Table S1). These include all 12 types of RDDs. Figure 1A shows the distribution by RDD type; T-to-C difference is the most common form, and transitions represent the four most common types (Fig. 1A). Similarly RDDs were also found in the other five wild-type strains, and frequencies range from 1.3 to 1.8 per 10,000 nucleotides (Fig. 1B; Supplemental Fig. S2A). RDDs are significantly enriched in coding exons (Fisher's exact test, $P<0.05$ ) (Supplemental Fig. S2B).

We examined how various inclusion criteria affect RDD identification (Supplemental Results). All 12 types of RDDs were found even when we applied more stringent thresholds for sequencing depth and RDD levels (Supplemental Fig. S2C,D). We also ensured that RDDs are detected by different alignment programs and parameters (Supplemental Results). We realigned the sequence reads with different programs and tested parameters for handling splice sites. We assessed error rates with internal standards and simulated RNA-seq data, as well as using a probability-based method. All the results support our conclusion that RDDs are found in yeast; they are not results of errors in sequencing or analysis of the sequence data. In addition, we used an independent method, droplet digital PCR, to validate the RDDs. Among the 20 RDD sites examined, 18 were also found by this method in yeast grown in a replicate culture. Figure 2 shows a C-to-G RDD in ADR1 (alcohol dehydrogenase II synthesis regulator 1 ) that was identified by sequencing and droplet digital PCR.

A

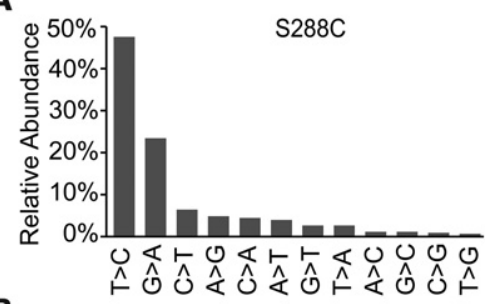

B

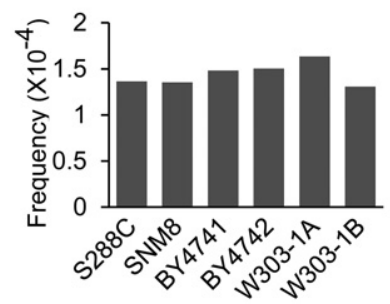

Figure 1. RNA-DNA sequence differences in S. cerevisiae. $(A)$ Twelve types of RDDs are found in S288C. (B) RDD frequencies are similar in six wild-type strains (1.3-1.8 per 10,000 nucleotides).
There are 334 RDD sites that are found in two or more of the six wild-type strains; among them 234 are in coding exons, eight are in introns, one is in snoRNA, and 91 in "intergenic regions" (including unannotated transcripts and UTRs beyond the annotated genic region) (Supplemental Table S2). RDD-containing genes include MTR4 that encodes an RNA helicase in the TRAMP complex, and DIP2 that encodes components of U3 snoRNP that processes pre-18S rRNA (Table 1). Of the 216 RDDs in coding sequences with annotated open reading frame (excluding dubious ORF), there seems to be no bias against nonsynonymous changes since 161 (74\%) are nonsynonymous and 55 (26\%) are synonymous changes.

\section{RNA forms of RDD-containing transcripts are translated into proteins}

Next, we asked whether RDD-containing transcripts are translated to proteins. We analyzed the yeast proteome by mass spectrometry. Previously, proteomic studies identified peptides by prediction based on DNA sequences; thus, peptides encoded by RNA forms at RDD sites would have been missed. Here, we embarked on finding peptides that result from RDDs. However, finding the RNA forms of proteins using shotgun mass spectrometry is challenging due to the "missing value" problem (Karpievitch et al. 2012; Nagaraj et al. 2012; Tyanova et al. 2014). Not all expressed proteins are identified by mass spectrometers; even when a protein is sequenced, only some of its peptides are captured. In addition, since most of the RDD levels are not very high, assuming one-to-one translation of RNA to proteins, the majority of the peptides at an RDD site will be the DNA form. To look for peptides that are encoded by RDDs, we first analyzed raw data generated by Mann and colleagues who carried out a comprehensive study of the yeast proteome (Nagaraj et al. 2012). We translated RNA sequences at RDD sites into amino acid sequences and incorporated them into our peptide search. Using the same proteomics software, MaxQuant (Nagaraj et al. 2012) as Mann and colleagues, we found peptides that are encoded by RNA rather than DNA sequences at RDD sites (Table 2). Encouraged by these results, we carried out our own mass spectrometry analysis with stringent thresholds sufficient for detecting mass difference between single amino acids (Methods). Just as with data from Mann and colleagues, we found peptides encoded by both DNA and RNA sequences at RDD sites (Table 2). For instance, a G-to-A RDD in RPN1, encoding a subunit of $26 \mathrm{~S}$ proteasome, is translated to DNA and RNA forms of the protein (V221I), as depicted by sequencing reads and mass spectra in Figure 3. RNA forms of Gip3 (S435L), Hsp90 (Q178E), and Tef1 (G34A) were found by mass spectrometry in both studies.

After finding the RDD-encoded peptides by whole proteome mass spectrometry, we attempted to enrich for protein isoforms resulting from RDDs. We began with one protein, Tup1, in a pilot study. There are two isoforms of Tup1, a DNA-encoded and an RNA-encoded form with alanine and valine as amino acid 459, respectively. For the enrichment of peptides for Tup1, we carried out immunoprecipitation with antibody against Tup1, then excised the protein band corresponding to the expected molecular weight of Tup 1 and performed mass spectrometry. However, that did not lead to an enrichment; rather, we got very few peptides corresponding to Tup 1 and no valine-form of the protein. Most likely this is because Tup 1 is a highly modified protein, and it works in a large protein complex. The post-translational modifications of Tup1 led to different electrophoretic pattern(s) than its unmodified form. In addition, since Tup1 is part of a large protein 

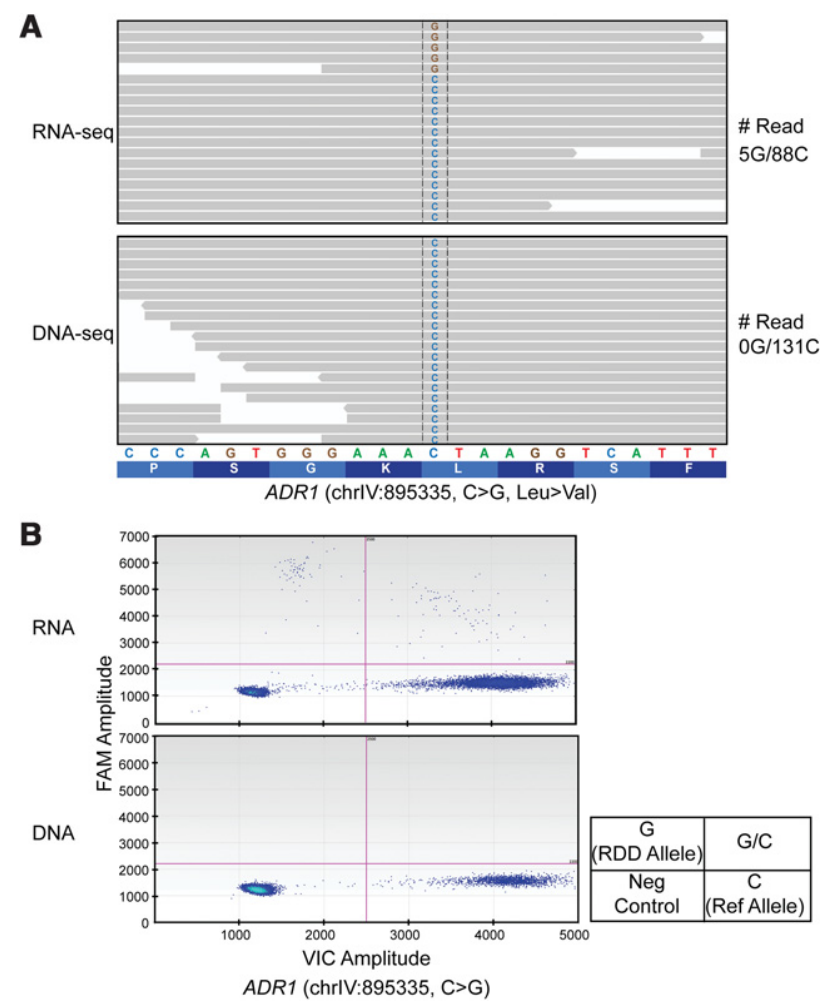

Figure 2. Representative example of an RDD identified by deep sequencing and droplet digital PCR. A C-to-G RDD in coding exon of ADR1 shown by RNA-seq and DNA-seq data on the Integrated Genomics Viewer $(A)$ and by droplet digital PCR $(B)$.

complex, the immunoprecipitation likely pulls down its interacting partners with similar sizes, which reduces our chance of detecting Tup1 itself (Krogan et al. 2006). Indeed, Cdc48, a known interacting partner of Tup1 with similar molecular weight, was detected in the immunoprecipitant. This suggests that unless we have ways to enrich specifically for a protein, mass spectrometry of the whole proteome may be a more practical approach for identifying protein isoforms from RDDs.

\section{Effect of RDD on protein structure and function}

Next, we examined whether the RDDs that lead to nonsynonymous changes in amino acids affect protein structures. The amino acid changes that result from RDDs are found throughout the proteins, including key active sites. For instance, a G-to-A RDD results in two forms of Rsc4 that have different sequences in the bromodomain. To characterize the impact of RDDs, we compared the predicted structures of DNA and RNA forms of the proteins (Zhang 2008). We focused on 10 RDD-encoded proteins that were detected by mass spectrometry (Table 2). The analysis showed some of the amino acids are exposed on protein surfaces that interact with ligands and/or other proteins, and others affect tertiary structures (Fig. 4). For example, modeling shows that the I49 (DNA form) and V49 (RNA form) of Arf2 have different orientations in the GTP/GDP binding domain. The RNA form (V49) of Arf2 is predicted to be more flexible for ligand binding than the DNA form; thus, the two protein isoforms likely have different substrate affinities (Cheng et al. 2006). In other proteins, RDDs affect tertiary structures. An example is Vph1, a subunit of the V-type $\mathrm{H}^{+}$ATPase that is required for assembly of the ATPase complex and maintenance of $\mathrm{pH}$ in yeast vacuoles. Figure 4 shows that the DNA (I319) and RNA (N319) forms of Vph1 have distinct folding properties (TM-score $=0.34$, in contrast to $>0.5$ for control proteins with similar structures; $\left.P<10^{-6}\right)$. Third, several RDDs are predicted to affect protein stabilities (Table 3; Worth et al. 2011). For instance, for the transcription repressor Tup1, the RNA form (V459) is predicted to be more stable $(\Delta \Delta \mathrm{G}=1.02)$ than the DNAform (A459) (Worth et al. 2011).

Next, we experimentally validated results from computational prediction and determined the functional consequences of RDDs by focusing on Tup1. We cloned the DNA and RNA forms of TUP1 ORF into plasmids under the control of a GAL1 promoter and induced their expression in yeast tup1 knockout strain. By Western blot, we showed that the protein level of the RNA form (V459) of Tup1 is higher than that of the DNA form (A459),

Table 1. Examples of RDDs in genes that play a role in ribosome biogenesis

\begin{tabular}{|c|c|c|c|c|c|c|c|c|c|c|}
\hline \multirow[b]{2}{*}{ Gene } & \multirow[b]{2}{*}{ Chr } & \multirow[b]{2}{*}{ Position } & \multirow[b]{2}{*}{ RDD } & \multirow[b]{2}{*}{ Amino acid } & \multicolumn{6}{|c|}{ RDD levels (\%) } \\
\hline & & & & & BY4741 & BY4742 & S288C & SNM8 & W303-1A & W303-1B \\
\hline NOP6 & IV & 77382 & $C>A$ & syn & - & - & - & 10.5 & - & 14.3 \\
\hline NOP14 & IV & 189726 & $\mathrm{~T}>\mathrm{A}$ & $D>E$ & 9.5 & - & - & 6.5 & 14 & - \\
\hline$R R P 1$ & IV & 617886 & $\mathrm{~T}>\mathrm{C}$ & $W>R$ & 5.8 & - & 5.6 & - & - & - \\
\hline ESF1 & IV & 1205918 & $\mathrm{~T}>\mathrm{C}$ & $W>R$ & - & - & 5.9 & - & - & 8.3 \\
\hline ENP2 & VII & 783759 & $\mathrm{~T}>\mathrm{C}$ & $S>P$ & - & - & - & 5.7 & 5 & - \\
\hline SDA1 & VII & 980392 & $C>A$ & $\mathrm{~N}>\mathrm{K}$ & 7.5 & - & - & 7.1 & - & - \\
\hline CIC1 & VIII & 211854 & $\mathrm{~T}>\mathrm{C}$ & $1>T$ & 11.5 & - & - & - & 5.3 & - \\
\hline MTR4 & $x$ & 344335 & $\mathrm{~T}>\mathrm{C}$ & $L>S$ & 10.5 & - & - & - & 8.7 & - \\
\hline DIP2 & XII & 400595 & $\mathrm{~T}>\mathrm{A}$ & syn & - & - & 12 & - & 9.8 & - \\
\hline ERB1 & XIII & 368739 & $C>T$ & syn & 5.8 & - & 5 & 6.3 & - & - \\
\hline ECM16 & XIII & 525831 & $A>T$ & $E>D$ & 5.1 & - & 5.9 & - & - & - \\
\hline RRP5 & XIII & 727288 & $G>A$ & $G>D$ & - & - & 8.3 & 7.1 & 6.9 & - \\
\hline KRI1 & XIV & 55287 & $\mathrm{G}>\mathrm{A}$ & $G>E$ & 5.6 & - & - & - & - & 6.1 \\
\hline LSM7 & XIV & 351083 & $G>A$ & syn & - & 8.7 & - & - & 6.6 & 11.8 \\
\hline HRR25 & $\mathrm{XVI}$ & 164682 & $\mathrm{~T}>\mathrm{C}$ & $M>T$ & - & - & 5.3 & - & 5.9 & - \\
\hline NOP4 & $\mathrm{XVI}$ & 471281 & $\mathrm{~T}>\mathrm{C}$ & $V>A$ & - & - & - & 9.1 & 5.3 & - \\
\hline
\end{tabular}

RDD levels for six wild-type yeast strains are shown.

(-) RDD with levels $<5 \%$ or where no RDD was detected; (syn) synonymous.

\section{Genome Research}

www.genome.org 
RNA-DNA sequence differences in budding yeast

Table 2. Peptides from RNA and DNA bases at RDD sites detected by mass spectrometry

\begin{tabular}{|c|c|c|c|c|c|c|}
\hline Protein & Peptide sequence & Encoded by & RDD position & $\begin{array}{l}\text { Codon } \\
\text { change }\end{array}$ & $\begin{array}{c}\text { AA } \\
\text { change }\end{array}$ & Source \\
\hline Abp1 & $\begin{array}{l}\text { IGNPLPGMHIEADNEEEPEENDDDWDDDEDEAAQPPLPSR } \\
\text { IGNPLPGMHIEADNEEEPEENDDDWDDEEDEAAQPPLPSR }\end{array}$ & $\begin{array}{l}\text { DNA } \\
\text { RNA }\end{array}$ & Chr III: 266393 & GAT > GAG & D442E & This study \\
\hline Arf2 & $\begin{array}{l}\text { LGEVITTIPTIGFNVETVQYK } \\
\text { LGEVITTIPTVGFNVETVQYK }\end{array}$ & $\begin{array}{l}\text { DNA } \\
\text { RNA }\end{array}$ & Chr IV: 216673 & $\mathrm{ATT}>\mathrm{GTT}$ & $149 \mathrm{~V}$ & This study \\
\hline Ded1 & $\begin{array}{l}\text { GLHEILTEAÑQEVPSFLK } \\
\text { GLHEILTEANQEVPP PFLK }\end{array}$ & $\begin{array}{l}\text { DNA } \\
\text { RNA }\end{array}$ & Chr XV: 724489 & $\mathrm{TCA}>\mathrm{CCA}$ & S345P & This study \\
\hline Fra1 & DAVCLVQYFAWLEQ̄QLAGR & RNA & Chr XII: 82920 & GTG $>$ GCG & V487A & This study \\
\hline Gcr1 & LIENYDWRR & RNA & Chr XVI: 415019 & $\mathrm{GGC}>\mathrm{GAC}$ & G724D & This study \\
\hline Gip3 & LAENLL_K & RNA & Chr XVI: 295344 & TCA $>$ TTA & S435L & $\begin{array}{l}\text { This study and Nagaraj } \\
\text { et al. (2012) }\end{array}$ \\
\hline Hsp90 & $\begin{array}{l}\text { EEVQELEELNK } \\
\text { EEVEELEELNK }\end{array}$ & $\begin{array}{l}\text { DNA } \\
\text { RNA }\end{array}$ & Chr XIII: 633135 & $\mathrm{CAA}>\mathrm{GAA}$ & Q178E & $\begin{array}{l}\text { This study and Nagaraj } \\
\text { et al. (2012) }\end{array}$ \\
\hline Kcs1 & NSFCNSSSPILTATNSR & RNA & Chr IV: 480262 & $\mathrm{TTA}>\mathrm{TCA}$ & L669S & This study \\
\hline Krs1 & $\begin{array}{l}\text { LAMFLTDSNTIR } \\
\text { RAMFLTDSNTIR }\end{array}$ & $\begin{array}{l}\text { DNA } \\
\text { RNA }\end{array}$ & Chr IV: 527109 & CTG $>$ CGG & L403R & This study \\
\hline Ksp1 & LSTEQKFK & RNA & Chr VIII: 269066 & ATG $>$ ACG & M697T & This study \\
\hline Mdm34 & ISL̄NLDPKK & RNA & Chr VII: 82991 & $\mathrm{TCC}>\mathrm{CCC}$ & S251P & Nagaraj et al. (2012) \\
\hline Noc2 & $\begin{array}{l}\text { SEQMELEEK } \\
\text { SEQTELEK }\end{array}$ & $\begin{array}{l}\text { DNA } \\
\text { RNA }\end{array}$ & Chr XV: 728017 & ATG $>$ ACG & M60T & This study \\
\hline Nup159 & TVTFFEK & RNA & Chr IX: 148342 & $\mathrm{TCT}>\mathrm{TT}$ & S493F & Nagaraj et al. (2012) \\
\hline Pop1 & LNĀDQFISSR & RNA & Chr XIV: 233520 & GTG $>$ GCG & V59A & This study \\
\hline Psk1 & $\begin{array}{l}\text { EGD̄EFEQSLR } \\
\text { EGDESEEQSL }\end{array}$ & $\begin{array}{l}\text { DNA } \\
\text { RNA }\end{array}$ & Chr I: 120439 & $\mathrm{TTC}>\mathrm{TCC}$ & F72S & This study \\
\hline Rho3 & $\begin{array}{l}\text { VALTAGPVATEVK } \\
\text { LALTAGPVATEVK }\end{array}$ & $\begin{array}{l}\text { DNA } \\
\text { RNA }\end{array}$ & Chr IX: 140376 & $\mathrm{GTT}>\mathrm{CTT}$ & V209L & Nagaraj et al. (2012) \\
\hline Rpn1 & 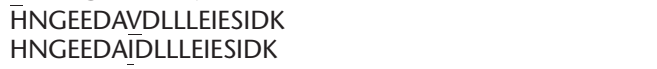 & $\begin{array}{l}\text { DNA } \\
\text { RNA }\end{array}$ & Chr VIII: 164051 & GTA $>$ ATA & V221I & This study \\
\hline Rsa4 & $\begin{array}{l}\text { TVRVWDINSQGR } \\
\text { TVRVRDINSQGR }\end{array}$ & $\begin{array}{l}\text { DNA } \\
\text { RNA }\end{array}$ & Chr III: 241443 & $\mathrm{TGG}>\mathrm{CGG}$ & W170R & Nagaraj et al. (2012) \\
\hline Tef1 & $\begin{array}{l}\text { SVEMHHEQLEQGVPGDNVGFNVK } \\
\text { SVEMHHEQLEQGVPDNVAFNVK }\end{array}$ & $\begin{array}{l}\text { DNA } \\
\text { RNA }\end{array}$ & Chr XVI: 701513 & GGT > GCT & G34A & $\begin{array}{l}\text { This study and Nagaraj } \\
\text { et al. (2012) }\end{array}$ \\
\hline Tup1 & $\begin{array}{l}\text { FLATGAEDR } \\
\text { FLV̄TGAEDR }\end{array}$ & $\begin{array}{l}\text { DNA } \\
\text { RNA }\end{array}$ & Chr III: 261077 & $\mathrm{GCA}>\mathrm{GTA}$ & A459V & This study \\
\hline Vph1 & 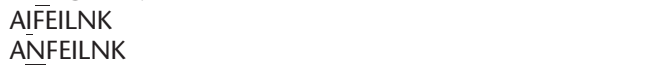 & $\begin{array}{l}\text { DNA } \\
\text { RNA }\end{array}$ & Chr XV: 829619 & $\mathrm{ATT}>\mathrm{AAT}$ & $1196 \mathrm{~N}$ & This study \\
\hline Vps5 & NGMEISLEEAIESQK & RNA & Chr XV: 455731 & GCG > GAG & A292E & Nagaraj et al. (2012) \\
\hline YIL108W & $\begin{array}{l}\text { TFPFVEEFTW̄WDTLFER } \\
\text { TFPFVEEFTR }\end{array}$ & $\begin{array}{l}\text { DNA } \\
\text { RNA }\end{array}$ & Chr IX: 161376 & TGG > CGG & W164R & This study \\
\hline Ypk1 & $\begin{array}{l}\text { GTINPSNSS̄VVPVR } \\
\text { GTINPSNSSVIPVR }\end{array}$ & $\begin{array}{l}\text { DNA } \\
\text { RNA }\end{array}$ & Chr XI: 205902 & GTC $>$ ATC & V66I & This study \\
\hline Ypt10 & DANIALIVFESGDVSSLQCAK & RNA & Chr II: 738095 & $\pi \mathrm{TG}>\mathrm{TCG}$ & L111S & This study \\
\hline Yta12 & SMVKVMLNDNEK & RNA & Chr XIII: 447368 & $\mathrm{GGA}>\mathrm{GAA}$ & G240E & Nagaraj et al. (2012) \\
\hline
\end{tabular}

Amino acids from RDDs are underscored. For each RDD-containing peptide, the corresponding DNA-form counterpart is also shown if detected by mass spectrometry.

whereas mRNA levels of both forms are similar (Fig. 5A,B). A cycloheximide chase study showed that the RNA form of Tup1 has a longer half-life than that of the DNA form (Fig. 5C). Together, these results are consistent with the prediction that the C-to- $\mathrm{U}$ RDD makes the Tup1 protein more stable. Next, we asked whether this difference in Tup1 protein stability affects its function. Because the main role of Tup1 is transcriptional regulation, to assess the effect of the RDD on function, we carried out RNA sequencing of yeast cells with or without TUP1 expression and identified 292 genes $(P<0.0001, t$-test) whose expression levels are influenced by Tup1. Previously, microarrays were used to identify Tup1-regulated genes; we compared our results to the 334 Tup1-regulated genes identified by Green and Johnson (2004), among them 243 are also expressed at significantly different levels $(P<0.01, t$-test $)$ in yeast with and without Tup1 in this study. Among these Tup1-regulated genes are MAL11, HXT2, and HSP12 that were previously found to be repressed by Tup1 (Green and Johnson 2004), and genes such as HIS4 and TAT2 that were induced by Tup1 (Tanaka and Mukai 2015). Tup1-Cyc8 does not directly bind to
DNA. As a corepressor complex, it affects gene expression by recruiting DNA-binding proteins mainly through the WD40 domain, where the amino acid affected by the RDD resides (Sprague et al. 2000; Malavé and Dent 2006). It is likely that DNA and RNA forms of Tup1 interact differently with some DNA-binding proteins, and therefore have differential effects on expression of some of its target genes. To examine this possibility, we compared the expression levels of the 292 genes in the yeast expressing either the DNA or the RNA form of Tup1. The results showed that 51 genes are differentially expressed (Fig. 5D); among them 42 had higher expression (>50\%) and nine genes had lower expression $(<50 \%)$ in yeast expressing the RNA form of Tup1. The 42 genes with higher expression in the RNA form of Tup1 were repressed by Tup1; thus, the RNA form conferred a lesser repressive effect on its target genes compared to the DNA form. These 42 genes include several stress responsive genes such as RCK1 and HUG1. Of the nine genes that showed lower expression, six genes including NDJ1 that encodes a telomere-associated protein that promotes meiotic recombination ( $\mathrm{Wu}$ and Burgess 2006), were induced by 
A

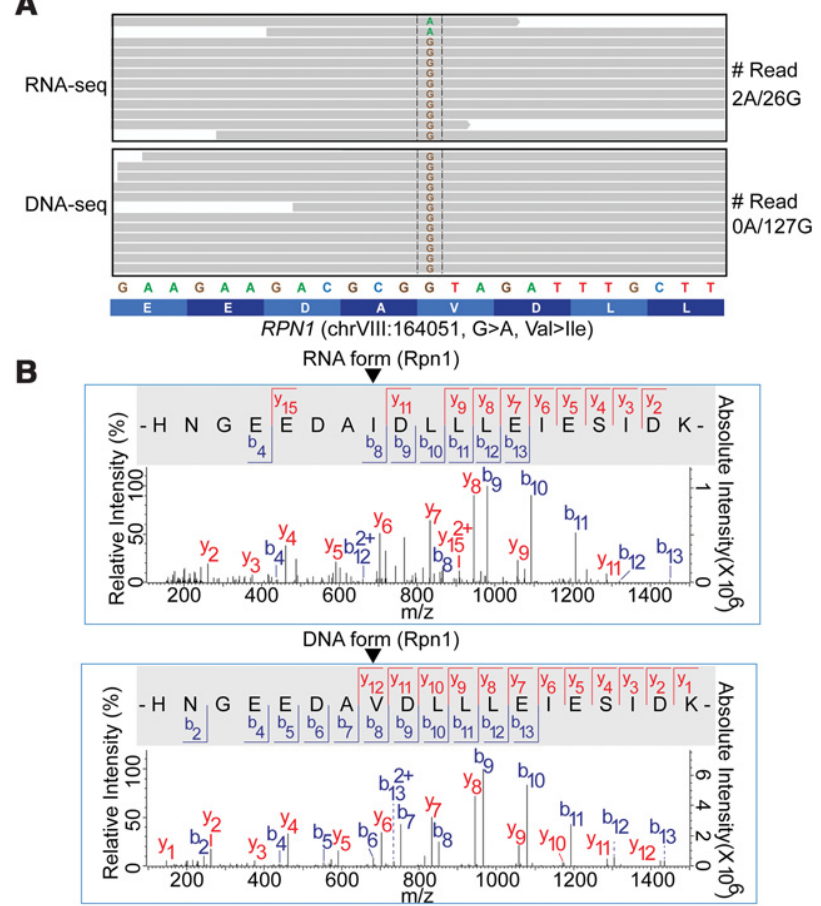

Figure 3. LC/MS-MS identified DNA-encoded valine and RNA-encoded isoleucine forms of Rpn1. (A) G-to-A RDD in the coding exon of RPN1 shown by RNA-seq and DNA-seq data on the Integrated Genomics Viewer. (B) Spectra from the MaxQuant Program for the resulting Valand lle-bearing peptides of Rpn1.

Tup1, but the RNA form of Tup1 induced these target genes to a lesser extent. Our results therefore show that although the RNA form of Tup 1 is more stable, it has a lesser effect on the expression levels of its target genes than the DNA form. This paradox in which a more stable protein has lower activity was described by Matthews and colleagues for lysozyme (Shoichet et al. 1995) and found for other proteins, including PTEN (Vazquez et al. 2000) and $\beta$-lactamase (Beadle et al. 1999). Lastly, to assess the cellular effect of RDD, we compared the stress response of yeast expressing the DNA and RNA form of Tup1. We found that yeast that expresses the RNA form of Tup1 is more sensitive to hygromycin B than the DNA form (Fig. 5E); this could result from the reduced activity of the valine-bearing form of Tup1. These results suggest that like other cotranscriptional processes, RDD produces transcripts with different functions and affects cellular phenotypes.

\section{Deaminases do not play a key role in yeast RDD formation}

After characterizing the RDDs, next we took advantage of yeast mutants to search for genes that are involved in RDD formation. The two known RNA editing enzymes in humans, ADAR and APOBEC, are deaminases that convert adenosine to inosine (then read by the translation machinery as guanosine), and cytidine to uridine. Knockdown of ADAR proteins in human B-cells resulted in a $>90 \%$ decrease in A-to-G editing (Wang et al. 2013). To look for equivalent pathways in yeast, we sequenced deaminase mutants and assessed for RDDs. We studied mutant strains of tRNA adenosine deaminases, $\operatorname{tad} 1^{-}, \operatorname{tad}_{2}{ }^{t s}$, and $\operatorname{tad} 3^{t s}$, and other deaminases such as $a a h 1^{-}$(adenine deaminase), amd1- (AMP deaminase), and $f c y 1^{-}$(cytosine deaminase). To confirm the mu- tant phenotypes, we first looked at the known editing sites in tRNA; as expected, we found a decrease in editing levels in the mutants. At nonpermissive temperature, the temperature sensitive mutant of the essential TAD2 gene $\left(\operatorname{tad} 2^{t s}\right)$ has a lower A-to-G editing level at position A34 of tRNA-serine (Supplemental Fig. S3A). Then, we asked whether the deaminases that target tRNA also affect mRNA. Unlike in tRNA, there was no difference in the mRNA editing patterns between mutants and wild-type strains. Other types of RDDs were also unchanged in the deaminase mutants. The relative abundance of all 12 types is highly similar between the mutants and wild-type controls (Supplemental Fig. S3B). For example, the average level of A-to-G RDD was $11 \%$ in wild-type yeast, and those among the mutants were $9 \%-12 \%$; for C-to-T, the level in wild-type strains was $9 \%$, and those in mutants were $7 \%-10 \%$. These results suggest that Tad1, Tad2, Tad3, Aah1, Amd1, and Fcy1 do not contribute to the majority of RDDs in mRNAs of yeast. A few other putative deaminase genes, including CDD1, DCD1, and RIB2, are essential for yeast survival, and null mutants are not available. These deaminases remain to be ruled out as enzymes contributing to RDDs.

\section{RDDs are dependent on R-loop formation}

Next, we assessed whether R-loops play a role in RDD formation. Previously, we showed RDDs do not arise during RNA synthesis by RNA Polymerase II nor as a direct consequence of incorporation of modified bases; rather, we showed that RDDs begin to occur in nascent RNA chains $\sim 55 \mathrm{nt}$ from the RNA Polymerase II active site (Wang et al. 2014). Because RDDs are found so soon after transcription, we posited that R-loops that often occur outside of the polymerase complex may be involved in RDD formation. Results from studying human cells with a gain-of-function mutation in senataxin (L389S) that leads to juvenile amyotrophic lateral sclerosis showed lower RDD frequency, consistent with the involvement of R-loops (Wang et al. 2014).

Yeast provides us with an opportunity to examine the connection between R-loops and RDD more deeply by using several approaches. We asked whether R-loops and RDDs colocalize and if yeast mutants with defective R-loops have altered RDD profiles. First, we mapped R-loops by DNA-RNA hybrid immunoprecipitation and deep sequencing (DRIP-seq) using the S9.6 antibody (Boguslawski et al. 1986). We identified more than 1500 R-loop peaks in BY4741. Then we asked whether RDDs colocalize with these R-loops and found that RDDs are significantly enriched $(P<0.0001)$ in R-loop regions (Supplemental Results; Fig. 6A).

Table 3. Differences in protein structure and stability between the RNA and DNA forms of proteins

\begin{tabular}{lccrl}
\hline Protein & RDD & Amino acid change & $\Delta \Delta \mathbf{C}^{\mathbf{a}}$ & Stability change \\
\hline Arf2 & A $>$ C & I49V & -0.41 & Neutral \\
Ded1 & T $>$ C & S527P & 0.32 & Neutral \\
Krs1 & T $>$ C & L557R & -3.25 & Destabilized \\
Noc2 & T $>$ C & M169T & -0.13 & Neutral \\
Psk1 & T $>$ C & F72S & -2.06 & Destabilized \\
Rpn1 & G $>$ A & V221I & -0.1 & Neutral \\
Rsa4 & T $>$ C & W304R & -0.79 & Destabilized \\
Tup1 & C $>$ T & A459V & 1.02 & Stabilized \\
Vph1 & T $>$ A & I319N & -5.16 & Destabilized \\
YIL108W & T $>$ C & W164R & -2.83 & Destabilized \\
\hline
\end{tabular}

${ }^{a}-0.5 \leq \Delta \Delta G \leq 0.5$ is considered neutral.

\section{Genome Research}

www.genome.org 


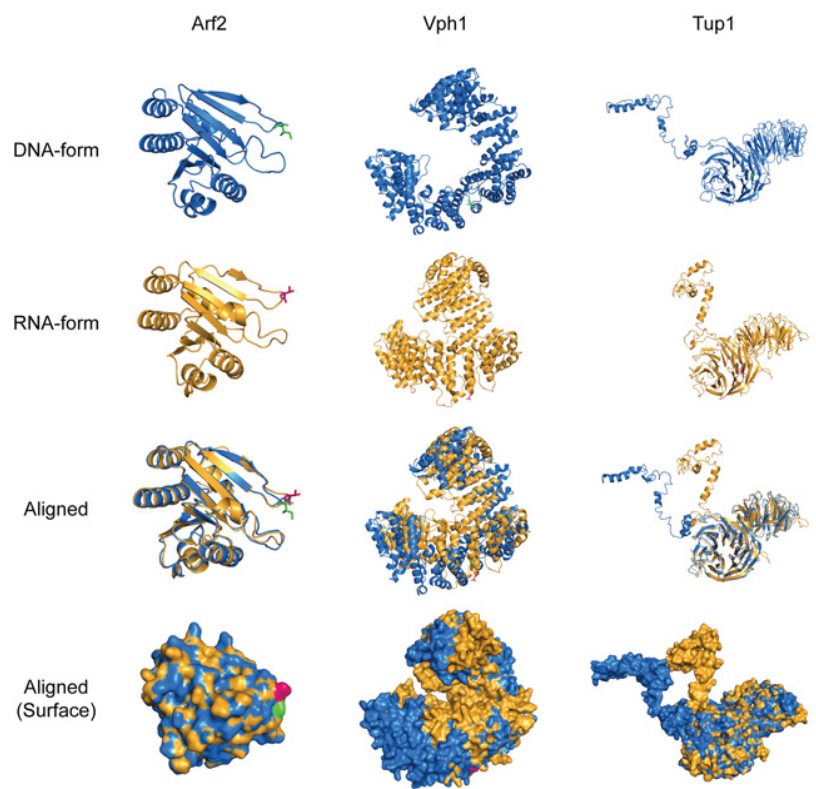

Figure 4. Three-dimensional structures of DNA and RNA forms of proteins. Arf2, Vph1, and Tup1 are shown as examples of DNA and RNA forms of the proteins with distinct features as predicted using I-TASSER.

A zoomed-in figure of a C-to-T RDD and R-loops in BUG1 is shown in Supplemental Figure S6.

Next, we search for genetic evidence that perturbation of Rloops affects RDDs. We took advantage of the different mechanisms that yeast has developed to resolve R-loops from directly unwinding the R-loops with the helicase, senataxin, to degrading the RNA with ribonuclease $\mathrm{H}$ and altering the supercoils in DNA with topoisomerase enzyme. First, we studied senataxin homolog (Sen1) in yeast. Proudfoot and colleagues showed that the yeast senataxin homolog (Sen1) plays a role in resolving R-loops and there is an accumulation of R-loops in the sen1-1 temperature-sensitive mutant (Mischo et al. 2011). Here, we quantified RDDs in the same senataxin mutant (Fig. 6B). By shifting the sen1-1 mutant to a nonpermissive temperature, we found significantly more R-loops $\left(P<0.02, \chi^{2}\right)$ and a genome-wide increase in RDD frequency (Fig. 6C). At the higher temperature with a loss of senataxin function, we identified more RDD sites and a trend for higher RDD levels. Examples include G-to-A sites in HSE1 and SEC26 (Fig. 6D). The higher RDD levels at the nonpermissive temperature allowed more RDD sites to be identified; some sites were found only in the nonpermissive temperature, whereas others that were present at $25^{\circ} \mathrm{C}$ but below our $5 \%$ level inclusion criterion had higher levels at $34^{\circ} \mathrm{C}$, and therefore are included as RDD sites. Sen 1 plays a role in pathways other than resolving R-loops. To ensure that the difference in RDD frequency in the yeast senataxin mutant is attributable to R-loop defects and not from other functions of senataxin, we examined additional yeast mutants that are defective in resolving RNA-DNA hybrids. We studied yeast deletion mutants of ribonuclease H1 (RNase H1, RNH1), and topoisomerase 1 (TOP1). RNase H1 resolves R-loops by hydrolysis of the RNA component of RNA-DNA hybrids (Stein and Hausen 1969; Keller and Crouch 1972; Wyers et al. 1973; Karwan et al. 1984). Topoisomerase 1 minimizes transcription-dependent R-loops by relaxing the supercoils that follow RNA polymerases (Drolet et al. 1995; Tuduri et al. 2009; El Hage et al. 2010;
Williams et al. 2013). As expected, using the S9.6 antibody that recognizes RNA-DNA hybrids, we confirmed that deletion of RNH1 or TOP1 leads to more R-loops, as in sen1-1 mutant (Fig. 6B). Then, we sequenced and studied RDDs in rnh1 and top1 mutants in BY4741 and SNM8 strains of S. cerevisiae. The results showed that genome-wide the $m h 1$ mutant has more RDDs $(\geq 25 \%)$ than wild-type controls in both strains (Fig. 6E). Similarly, loss of TOP1 leads to $\sim 10 \%$ more RDDs. As in the senataxin mutants, the RDD levels are significantly higher in both mutants $\left(P \leq 0.006, \chi^{2}\right)$. Figure $6 \mathrm{~F}$ shows examples of RDD sites where the rnh1 and top1 mutants have higher levels compared to the wild-type yeast. Together these findings show that yeasts that have more R-loops, from different mechanisms ranging from deficiencies in senataxin, to the loss of ribonuclease H1 and topoisomerase 1 activities, have more RDDs.

\section{Discussion}

Nascent RNAs are highly modified through splicing and alternative use of start and termination sites, which generate mature RNAs and proteins of different structures. In some cases, the different transcripts from the same DNA templates even have opposing functions, such as BCL-x in which one splice form (BCL-xS) promotes apoptosis and another form (BCL-xL) inhibits apoptosis (Boise et al. 1993). Besides splicing, another way to diversify transcripts is through changes in RNA sequences by RNA editing, such as those mediated by the ADAR proteins. Previously, RNA editing was reported in organisms from kinetoplastids to plants and human cells, but not in yeast. Here, we show that RNA-DNA sequence differences occur at about the same frequency in yeast $(1 / 10,000)$ as in human cells. All 12 types of RDDs were found. Our mutant screens showed that RDD formation is associated with RNA-DNA hybrids. Comparison of DNA and RNA sequences of mutants known to have more R-loops (Wyers et al. 1973; Tuduri et al. 2009) reveals that all the mutants have higher RDD frequencies than wild-type strains. This effect is specific because consistent changes in RDD frequency and level were found among yeasts with R-loop defects from loss-of-function mutations in senataxin, ribonuclease $\mathrm{H} 1$, or topoisomerase 1 but not in other mutants such as those with defective deaminases. The increase in RDD is not just at a few sites, but rather there is an increase genome-wide.

Previously, our results in human cells showed that RDDs are formed in nascent RNA soon after RNA synthesis and suggested that their formation is coupled to R-loops. Here in yeast, we provide molecular and genetic evidence that RDDs are coupled to Rloops. We posit that the R-loops promote RNA structures that facilitate RDD formation. Multistep processes must be involved in RDD formation, in particular, for the transversion events. For the sites reported here, the RDD types are highly consistent. For example, at an A-to-C site, all RDD-containing transcripts contain a $\mathrm{C}$ instead of multiple alleles. To us, this suggests that RNA modification is not likely to explain the RDDs, because reverse transcriptases misincorporate nucleotides when they encounter modified bases. At RDD sites, we do not see the multiallelic patterns that are hallmarks of RNA modifications, rather the same types of nucleotides are observed. Thus, RNA modifications do not explain most of the RDDs. Rather, we favor enzymatic steps that convert one nucleotide to another for the transition events, and multistep processes that may include abasic intermediates for the transversions. It remains unknown what confers the specificity in RDD formation. Organisms such as trypanosomes use 
A

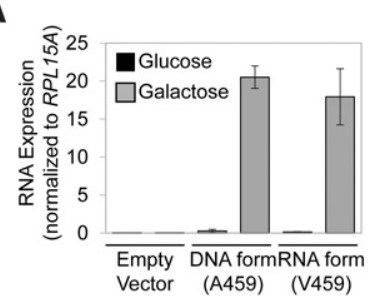

$\mathbf{B}$

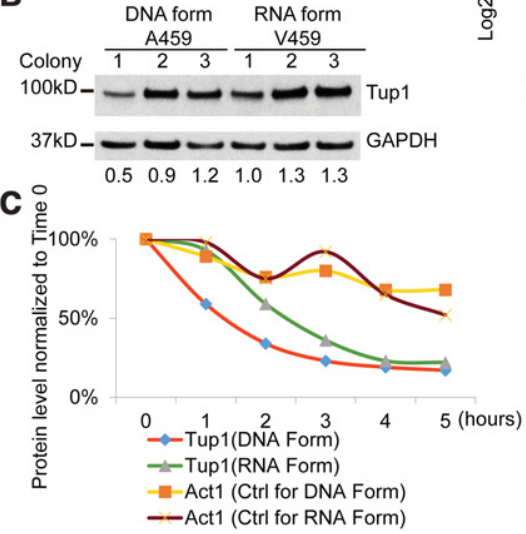

D.

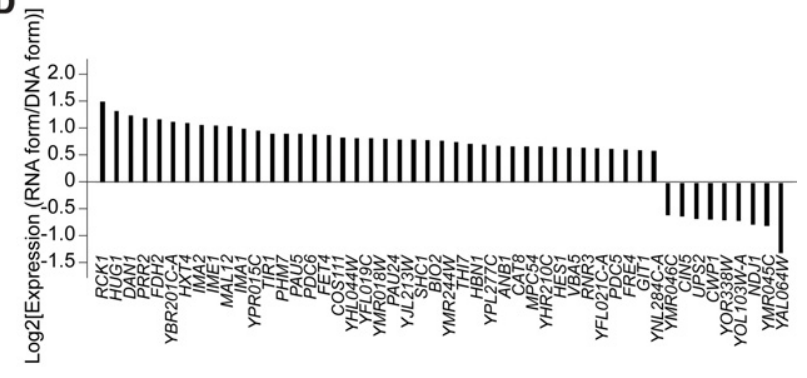

E

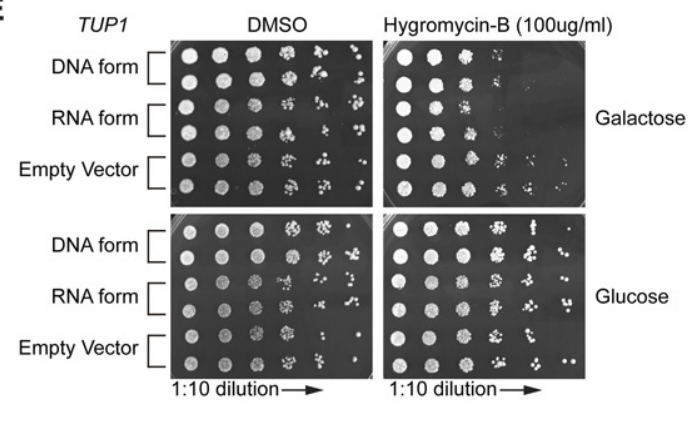

Figure 5. Effects of an RDD in TUP1 on protein stability and function. (A) DNA form and RNA form of TUP1 were cloned into yeast plasmids under the control of a GAL1 promoter, and expression of each form was induced by galactose. The two forms had similar mRNA levels, as determined by real-time RTPCR. Yeast colonies $(n=3)$ transformed with empty vector, DNA form, and RNA form of TUP1 are shown. Error bars represent standard deviation of three colonies. (B) Protein level of the RNA form of Tup1 is higher than that of DNA form. Whole-cell extracts of the same colonies in $A$ were analyzed by Western blot. Intensity of each band of Tup1 is quantified using Imagel and normalized to that of GAPDH, and their values are shown below each band. (C) Cycloheximide chase assay showed that RNA form of Tup1 is more stable than the DNA form. The Act1 level from each transformant was measured as control. $(D)$ Genes that are differentially regulated by DNA and RNA form of Tup1. Gene expression levels were measured by RNA-seq of yeast cells expressing either form of Tup1. (E) Yeast expressing the RNA form of Tup1 is more sensitive to hygromycin B. Yeast cells were cultured in liquid medium; 10x serial dilutions were spotted onto plates containing hygromycin B or DMSO control to measure cell growth. Tup1 expression is induced by galactose in plates. Cells were also spotted on plates containing glucose as a negative control.

short RNAs as guides for editing RNA (for review, see Benne 1992). Guide RNAs have not been identified in yeast nor in human; however since many small RNAs remain to be characterized, we cannot exclude this possibility.

To begin to explore the functional consequences of RDDs, we studied a C-to-U site that results in a valine substitution for alanine in the WD40 domain of Tup1. This protein in conjunction with Cyc8 regulates gene expression by recruiting DNA-binding proteins to target genes. The WD40 domain is the platform for these protein interactions. We showed the RNA form (V459) of Tup1 is more stable than the DNA form yet its regulatory activity on more than 50 target genes is lower. Matthews and colleagues suggested that to maximize their activities, proteins can adopt a conformation that is less stable. They first showed supporting data in lysozyme (Shoichet et al. 1995); since then, they and others have provided many additional examples. Here the RDD in TUP1 appeared to make the protein more stable yet less active. This could be a mechanism to fine tune the kinetics and the expression levels of its target genes.

To conclude, since the initial identification of RDDs in human cells (Li et al. 2011), additional studies have enabled us to characterize further this cotranscriptional RNA processing step. By identifying RDDs in yeast, we show that they are conserved. Characterization of transcripts with RDDs and the resulting protein isoforms shows that RDDs, like alternate splicing, diversify transcriptome and proteome by providing additional RNA and protein isoforms with different functions and/or regulation. In ad- dition, we show that RDDs are coupled to R-loops. This information should lead us and others closer to uncovering mechanistic details that underlie RDD formation and determining their functional roles.

\section{Methods}

\section{Yeast strains}

Yeast strains used in this study are listed in Supplemental Table S3. Yeast cultures and deep sequencing of DNA and RNA are described in Supplemental Methods.

\section{DNA-RNA immunoprecipitation and deep sequencing (DRIP-seq)}

Immunoprecipitation procedure was adapted from previous studies (Skourti-Stathaki et al. 2011; Ginno et al. 2012), and $1 \times 10^{8}$ yeast cells were used for each immunoprecipitation. Genomic DNA containing R-loops was purified using MasterPure Yeast DNA Purification Kit (Epicentre). DNA was fragmented with a cocktail of five restriction enzymes (HindIII, EcoRI, BsrGI, XbaI, and SspI) (New England Biolabs). Five micrograms S9.6 monoclonal antibody (gift from Dr. Stephen H. Leppla at NIH) or nonspecific mouse IgG was used for each immunoprecipitation. Input and precipitated DNA was made into sequencing libraries using DNA SMART ChIP-Seq Kit (Clontech). 
A

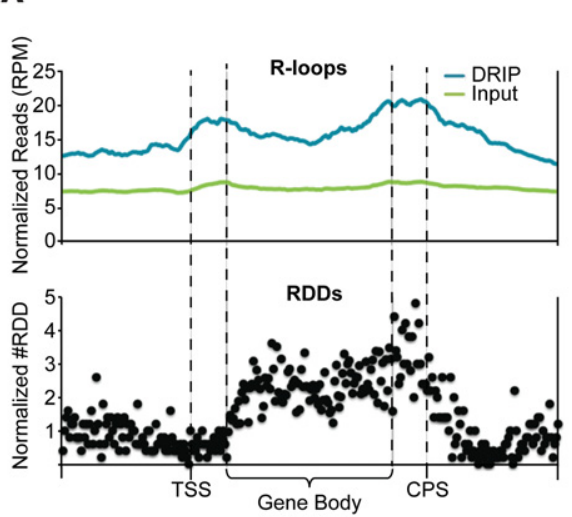

E

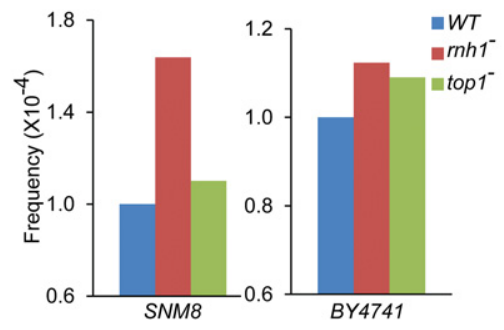

$\mathbf{F}$
B

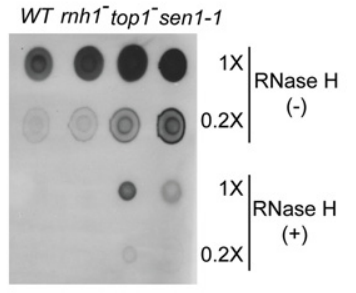

C

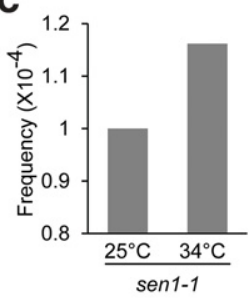

D IST2 C>G II:422475 SKY1 T>A XIII:69982 SCR1 C>T V:441995 HSE1 G>A VIII:103956 IKS1 C>T X:328683 HTZ1 G>A XV:303947 ICL1 T>C V:286264 FCP1 A>T XIII:820474 SEC26 G>A IV:940302
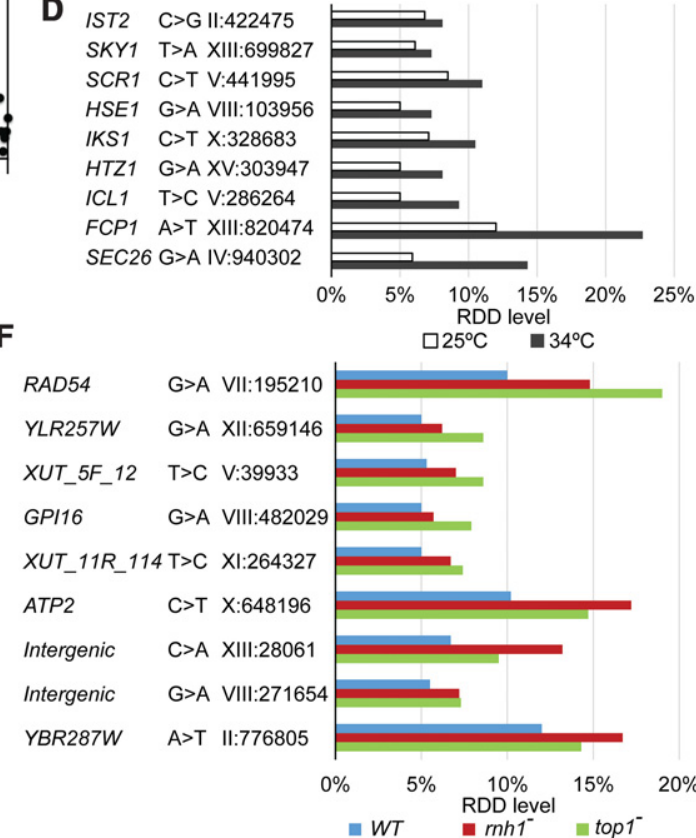

Figure 6. RDDs and R-loops are coupled. (A) Genome-wide distribution of R-loops and RDDs. Metagene plots show overlap between R-loops and RDDs: (TSS) transcription start site; (CPS) cleavage and polyadenylation signal; (gene body) annotated coding sequence in reference genome. (B) Nucleic acid blots probed with S9.6 antibody show more RNA-DNA hybrids in $r n h 1^{-}$, top $1^{-}$, and sen 1-1 mutants compared to wild-type control. In the temperaturesensitive mutant of sen 1-1, at nonpermissive temperature, RDD frequency $(C)$ and levels $(D)$ are higher. ( $E$ ) In two different strain backgrounds, RDD frequencies are higher in $r n h 1^{-}$and top $1^{-}$mutants than in wild-type control. (F) RDD levels are higher in $r n h 1^{-}$and top $1^{-}$mutants than in wild-type control. Two Xrn1-sensitive unstable transcripts (XUTs) are annotated according to XUT track in the SGD genome browser (van Dijk et al. 2011).

\section{Functional analysis of RNA form of Tupl}

The pBY011-TUP1 plasmid (Catalog \#ScCD00095253, Harvard PlasmID repository) contains GAL1 promoter and the DNA form of TUP1. The RNA form of TUP1 was generated using the QuikChange II XL Site-Directed Mutagenesis Kit (Stratagene). Yeast cells were transformed with either pBY011-TUP1-A459 (DNA form), pBY011-TUP1-V459 (RNA form), or empty vector using the lithium acetate method. Gene induction, drug sensitivity, and cycloheximide chase assay are described in detail in Supplemental Methods.

\section{R-loop dot blot using S9.6 antibody}

Two hundred fifty nanograms of DNA containing R-loops from each strain was incubated with 1 unit of RNase H (\#M0297, NEB) or mock for no RNase $\mathrm{H}$ digestion control, in $1 \times$ RNase $\mathrm{H}$ digestion buffer for $12 \mathrm{~h}$ at $37^{\circ} \mathrm{C}$. DNA was phenol extracted and ethanol precipitated and reconstituted in $10 \mu \mathrm{L}$ TE buffer. Five microliters $1 \times$ or $0.2 \times$ titration of DNA solution was loaded to nitrocellulose membrane, air dried for $30 \mathrm{~min}$, and baked for $2 \mathrm{~h}$ at $80^{\circ} \mathrm{C}$. The membrane was blocked in 5\% BSA for $1 \mathrm{~h}$ and incubated with 1:1000 S9.6 antibody (gift from the Proudfoot laboratory)
(Boguslawski et al. 1986) overnight at $4^{\circ} \mathrm{C}$ in order to detect RNA-DNA hybrids.

\section{Analysis of sequencing data}

Sequence reads were preprocessed as follows: Adapter sequences from the end of reads were trimmed using the program fastx_clipper from FASTX-Toolkit (Hannon Lab). Low-quality sequences at ends of reads represented by a stretch of "\#" in the quality score string in FASTQ file were also removed. PolyA (more than five consecutive As) at the end of reads were removed. Reads that were $>35$ nt after trimming were included for further analyses. Sequence reads were then aligned to sacSer3 reference using GSNAP (Version 2013-10-28) (Wu and Nacu 2010) with the following parameters and BAM files were generated: Mismatches $\leq$ [read length +2 )/12-2]; Mapping score $\geq 20$; Soft-clipping on (-trim-mismatchscore $=-3$ ). The reads with identical sequences were counted as one read in order to remove possible PCR duplicates.

Expression levels of RNA transcripts were analyzed using Cufflinks (version 2.1.1.) at default parameters (Trapnell et al. 2010 ) and the RPKM (reads per kilobase per million mapped reads) value is reported as the expression value. Genes with RPKM $>1$ in at least $75 \%$ samples were retained for downstream analysis. To 
identify genes whose expression levels are influenced by TUP1, we compared gene expression in yeast with (galactose-induced) and without (empty vector and glucose-repressed) TUP1 by Student's $t$-test. Among the 292 genes with nominal $P<0.0001$, we determined fold difference of expression levels in yeast expressing valine- (RNA form) versus alanine-containing (DNA form) of TUP1.

To identify R-loop peaks from sequencing data, read depth at each nucleotide site was calculated using BamTools (Barnett et al. 2011). Only genomic sites covered by sequence reads in input samples are retained for further analysis. An R-loop peak is called in DRIP samples when contiguous sequence reads cover a genomic region with sequencing depth $\geq 20$ RPM (reads per nucleotide per million of uniquely aligned reads), and fold enrichment of S9.6 antibody over input $\geq 2.5$-fold.

\section{RDD identification}

RNA-DNA sequence differences were identified as previously described with some modifications (Li et al. 2011; Wang et al. 2013, 2014). In DNA-seq data, we required a minimum coverage of 10 reads at a given site, and the DNA sequence at this site to be $100 \%$ concordant (no reads containing alternate alleles). For each site that passed DNA-seq coverage cutoff, we compared RNA-seq read sequence to its corresponding DNA sequence from the same strain, requiring four criteria for RDD identification: (1) a minimum of 10 RNA-seq reads covering this site; (2) RDD level $\geq 5 \%$ (level $=[\#$ of RNA-seq reads containing non-DNA allele]/ [\# all RNA-seq reads covering a given site]); (3) a minimum of two nonidentical RNA-seq reads containing RDD; and (4) Phred score $\geq 20$.

We applied additional filtering steps and statistical analyses to ensure correct RDD identification (Supplemental Methods and Supplemental Results). We picked 20 sites of each type that are suitable for primer and assay design for droplet digital PCR and experimentally validated them (Supplemental Methods).

\section{Mass spectrometry analysis}

For proteins encoded by RDDs to be identified by mass spectrometry, RDD sequence information needed to be incorporated into a protein database. For each nonsynonymous RDD identified in six wild-type strains, we translated the RNA sequence into amino acid sequence. Thus, we constructed a protein database containing both yeast protein sequences coded by reference sequence (sacCer3) and those coded by RDDs. This database includes 5887 proteins, of which 2336 proteins are represented by both DNAform and RNA-form sequences.

Yeast proteomic data generated by the Mann group using a Single-shot Ultra HPLC Runs on a Bench Top Orbitrap were downloaded from Tranche proteome repository (Nagaraj et al. 2012). In our own LC/MS-MS analysis, $5 \times 10^{7}$ yeast cells of S288C and W303-1A collected from exponential cultures were frozen in liquid nitrogen and ground using a Retsch ball mill homogenizer (Retsch). Homogenized cells were then dissolved in $1 \mathrm{~mL}$ lysis buffer (20 mM Tris $\mathrm{HCl} \mathrm{pH} \mathrm{8,} 137 \mathrm{mM} \mathrm{NaCl}, 10 \%$ glycerol 1\% Nonidet P-40, 2 mM EDTA), and $60 \mu$ total protein was prefractionated and digested as previously described (Li et al. 2011).

MaxQuant typically performs an initial search, mass recalibration, and then carries out the main searches in order to achieve high accuracy. We applied a peptide tolerance $(4.5 \mathrm{ppm})$ that is much more stringent than required to detect a small mass difference between single amino acids. Raw files were analyzed using MaxQuant vesion 1.5.1.2 (Cox and Mann 2008) and searched against the aforementioned RDD-containing protein database. The following search parameters were applied: initial search with peptide tolerance of $20 \mathrm{ppm}$, main search after mass recalibration with peptide tolerance of $4.5 \mathrm{ppm}$, parent ion mass tolerance of 0.3 $\mathrm{Da}$, MS/MS tolerance 0.5 Da, complete carbaminomethyl modification of cysteine and variable N-terminal acetylation and methionine oxidation, allowing up to one trypsin miscleavage, protein false discovery rate $<1 \%$, and peptide false discovery rate $<1 \%$ (determined by decoy database search). To confirm uniqueness of peptides, we searched the sequence of each identified RDD-encoded peptides against yeast protein databases using BLAST. None of the RDD-encoded peptides matched known peptides, confirming these peptides are not encoded by other regions of the genome. This ensures that each RDD-form peptide is truly unique.

To assess the false discovery rate of peptide search, we generated a negative control database. We used the target-decoy strategy, a method widely used to estimate false positive peptides, developed by Gygi's group (Elias and Gygi 2010). In this method, a control protein database is generated by reversing the amino acid sequence of each protein, and the number of peptides detected from the decoy search is used to determine FDR. Choosing a randomized control for proteomic analysis is challenging. A simple scrambled amino acid sequence will differ from a biological sample in amino acid composition, location of tryptic sites, length of tryptic peptides, mass accuracy, and probability to be detected. The decoy method minimizes such drawbacks. The FDR of peptide in our analysis is $1 \%$, as determined by this method.

\section{Protein structure prediction}

Three-dimensional structures of proteins were predicted using ITASSER without restraints and templates (Zhang 2008). The TMscore (value 0-1 with 1 indicating the perfect match) was used to measure structural similarity between DNA-form and RNA-form models. Protein stability is predicted as previously published (Worth et al. 2011).

\section{Data access}

The DNA and RNA sequencing and DRIP-seq data from this study have been submitted to the European Nucleotide Archive (ENA; http://www.ebi.ac.uk/ena/) under study accession number PRJEB8021. The mass spectrometry data have been submitted to the PeptideAtlas database (http://www.peptideatlas.org/) with the identifier PASSO0687.

\section{Acknowledgments}

We thank Drs. Susana Cerritelli, Robert Crouch, Daniel Klionsky, Thomas Kunkel, and Rolf Sternglanz for providing yeast strains, insightful suggestions, and discussions; Drs. Nicholas Proudfoot, Konstantina Skourti-Stathaki, and Stephen Leppla for providing S9.6 antibody and discussions; Dr. John Lis for the many discussions and encouragements; Dr. Hsin-Yao Tang at Wistar Proteomic Center for technical support and discussion on proteomic analysis; Mr. Hongjiu Zhang in Dr. Yang Zhang's laboratory for help and suggestions on protein structure prediction; and Ms. Jennifer Fox and Ms. Yaojuan Liu for technical support. This work was supported by the National Institutes of Health and the Howard Hughes Medical Institute.

Author contributions: I.X.W. and V.G.C. conceived and supervised the project and designed experiments. I.X.W. and G.R. carried out experiments. Z.Z. and C.G. processed next-generation sequencing data and analyzed RDD. I.X.W., Y.G.C., Z.Z., and G.R. analyzed proteomic data. H.K. performed statistical analyses. I.X.W. and V.G.C. wrote the manuscript with contributions from all authors.

\section{Genome Research}

www.genome.org 


\section{References}

Albertin CB, Simakov O, Mitros T, Wang ZY, Pungor JR, Edsinger-Gonzales E, Brenner S, Ragsdale CW, Rokhsar DS. 2015. The octopus genome and the evolution of cephalopod neural and morphological novelties. Nature 524: 220-224.

Alon S, Mor E, Vigneault F, Church GM, Locatelli F, Galeano F, Gallo A, Shomron N, Eisenberg E. 2012. Systematic identification of edited microRNAs in the human brain. Genome Res 22: 1533-1540.

Avesson L, Barry G. 2014. The emerging role of RNA and DNA editing in cancer. Biochim Biophys Acta 1845: 308-316.

Bahn JH, Lee JH, Li G, Greer C, Peng G, Xiao X. 2012. Accurate identification of A-to-I RNA editing in human by transcriptome sequencing. Genome Res 22: 142-150.

Barnett DW, Garrison EK, Quinlan AR, Strömberg MP, Marth GT. 2011. BamTools: a C++ API and toolkit for analyzing and managing BAM files. Bioinformatics 27: 1691-1692.

Bar-Yaacov D, Avital G, Levin L, Richards AL, Hachen N, Rebolledo Jaramillo B, Nekrutenko A, Zarivach R, Mishmar D. 2013. RNA-DNA differences in human mitochondria restore ancestral form of 16S ribosomal RNA. Genome Res 23: 1789-1796.

Bazak L, Haviv A, Barak M, Jacob-Hirsch J, Deng P, Zhang R, Isaacs FJ, Rechavi G, Li JB, Eisenberg E, et al. 2014. A-to-I RNA editing occurs at over a hundred million genomic sites, located in a majority of human genes. Genome Res 24: 365-376.

Beadle BM, McGovern SL, Patera A, Shoichet BK. 1999. Functional analyses of AmpC $\beta$-lactamase through differential stability. Protein Sci 8: 1816-1824.

Benne R. 1992. RNA editing in trypanosomes. The us(e) of guide RNAs. Mol Biol Rep 16: 217-227.

Benne R, Van Den Burg J, Brakenhoff JP, Sloof P, Van Boom JH, Tromp MC. 1986. Major transcript of the frameshifted coxll gene from trypanosome mitochondria contains four nucleotides that are not encoded in the DNA. Cell 46: 819-826.

Boguslawski SJ, Smith DE, Michalak MA, Mickelson KE, Yehle CO, Patterson WL, Carrico RJ. 1986. Characterization of monoclonal antibody to DNA - RNA and its application to immunodetection of hybrids. I Immunol Methods 89: 123-130.

Boise LH, González-García M, Postema CE, Ding L, Lindsten T, Turka LA, Mao X, Nuñez G, Thompson CB. 1993. bcl-x, a bcl-2-related gene that functions as a dominant regulator of apoptotic cell death. Cell 74: 597-608.

Chen L. 2013. Characterization and comparison of human nuclear and cytosolic editomes. Proc Natl Acad Sci 110: E2741-E2747.

Chen R, Mias GI, Li-Pook-Than J, Jiang L, Lam HY, Chen R, Miriami E, Karczewski KJ, Hariharan M, Dewey FE, et al. 2012. Personal omics profiling reveals dynamic molecular and medical phenotypes. Cell 148: 1293-1307.

Cheng X, Lu B, Grant B, Law RJ, McCammon JA. 2006. Channel opening motion of $\alpha 7$ nicotinic acetylcholine receptor as suggested by normal mode analysis. J Mol Biol 355: 310-324.

Cox J, Mann M. 2008. MaxQuant enables high peptide identification rates, individualized p.p.b.-range mass accuracies and proteome-wide protein quantification. Nat Biotechnol 26: 1367-1372.

Drolet M, Phoenix P, Menzel R, Massé E, Liu LF, Crouch RJ. 1995. Overexpression of RNase $\mathrm{H}$ partially complements the growth defect of an Escherichia coli $\Delta$ topA mutant: R-loop formation is a major problem in the absence of DNA topoisomerase I. Proc Natl Acad Sci 92: 3526-3530.

El Hage A, French SL, Beyer AL, Tollervey D. 2010. Loss of Topoisomerase I leads to R-loop-mediated transcriptional blocks during ribosomal RNA synthesis. Genes Dev 24: 1546-1558.

Elias JE, Gygi SP. 2010. Target-decoy search strategy for mass spectrometrybased proteomics. In Proteome bioinformatics (ed. Hubbard SJ, Jones AR), Vol. 604, pp. 55-71. Humana Press, Totowa, NJ.

Engel SR, Dietrich FS, Fisk DG, Binkley G, Balakrishnan R, Costanzo MC Dwight SS, Hitz BC, Karra K, Nash RS, et al. 2013. The reference genome sequence of Saccharomyces cerevisiae: then and now. G3 (Bethesda) 4: 389-398.

Garrett S, Rosenthal JJC. 2012. RNA editing underlies temperature adaptation in $\mathrm{K}^{+}$channels from polar octopuses. Science 335: 848-851.

Ginno PA, Lott PL, Christensen HC, Korf I, Chédin F. 2012. R-loop formation is a distinctive characteristic of unmethylated human CpG island promoters. Mol Cell 45: 814-825.

Green SR, Johnson AD. 2004. Promoter-dependent roles for the Srb10 cyclin-dependent kinase and the Hda1 deacetylase in Tup1-mediated repression in Saccharomyces cerevisiae. Mol Biol Cell 15: 4191-4202.

Gualberto JM, Lamattina L, Bonnard G, Weil JH, Grienenberger JM. 1989. RNA editing in wheat mitochondria results in the conservation of protein sequences. Nature 341: 660-662.
Han SW, Kim HP, Shin JY, Jeong EG, Lee WC, Kim KY, Park SY, Lee DW, Won JK, Jeong SY, et al. 2014. RNA editing in RHOQ promotes invasion potential in colorectal cancer. J Exp Med 211: 613-621.

Hiesel R, Wissinger B, Schuster W, Brennicke A. 1989. RNA editing in plant mitochondria. Science 246: 1632-1634.

Ju YS, Kim JI, Kim S, Hong D, Park H, Shin JY, Lee S, Lee WC, Kim S, Yu SB, et al. 2011. Extensive genomic and transcriptional diversity identified through massively parallel DNA and RNA sequencing of eighteen Korean individuals. Nat Genet 43: 745-752.

Karpievitch YV, Dabney AR, Smith RD. 2012. Normalization and missing value imputation for label-free LC-MS analysis. BMC Bioinformatics 13 (Suppl 16): S5.

Karwan R, Blutsch H, Wintersberger U. 1984. A ribonuclease $\mathrm{H}$ from yeast stimulates DNA polymerase in vitro. Adv Exp Med Biol 179: 513-518.

Kawahara Y, Ito K, Sun H, Aizawa H, Kanazawa I, Kwak S. 2004. Glutamate receptors: RNA editing and death of motor neurons. Nature 427: 801 .

Keller W, Crouch R. 1972. Degradation of DNA RNA hybrids by ribonuclease $\mathrm{H}$ and DNA polymerases of cellular and viral origin. Proc Natl Acad Sci 69: 3360-3364.

Kleinman CL, Majewski J. 2012. Comment on "Widespread RNA and DNA sequence differences in the human transcriptome". Science 335: 1302; author reply 1302 .

Klimek-Tomczak K, Mikula M, Dzwonek A, Paziewska A, Karczmarski J Hennig E, Bujnicki JM, Bragoszewski P, Denisenko O, Bomsztyk K, et al. 2006. Editing of hnRNP K protein mRNA in colorectal adenocarcinoma and surrounding mucosa. Br J Cancer 94: 586-592.

Krestel H, Raffel S, von Lehe M, Jagella C, Moskau-Hartmann S, Becker A Elger CE, Seeburg PH, Nirkko A. 2013. Differences between RNA and DNA due to RNA editing in temporal lobe epilepsy. Neurobiol Dis 56: 66-73.

Krogan NJ, Cagney G, Yu H, Zhong G, Guo X, Ignatchenko A, Li J, Pu S, Datta N, Tikuisis AP, et al. 2006. Global landscape of protein complexes in the yeast Saccharomyces cerevisiae. Nature 440: 637-643.

Lee RD, Song MY, Lee JK. 2013. Large-scale profiling and identification of potential regulatory mechanisms for allelic gene expression in colorectal cancer cells. Gene 512: 16-22.

Li M, Wang IX, Li Y, Bruzel A, Richards AL, Toung JM, Cheung VG. 2011. Widespread RNA and DNA sequence differences in the human transcriptome. Science 333: 53-58.

Li M, Wang IX, Cheung VG. 2012. Response to Comments on "Widespread RNA and DNA sequence differences in the human transcriptome". Science 335: 1302.

Lin W, Piskol R, Tan MH, Li JB. 2012. Comment on "Widespread RNA and DNA sequence differences in the human transcriptome". Science 335: 1302; author reply 1302.

Malavé TM, Dent SYR. 2006. Transcriptional repression by Tup1-Ssn6. Biochem Cell Biol 84: 437-443.

Martinez HD, Jasavala RJ, Hinkson I, Fitzgerald LD, Trimmer JS, Kung HJ, Wright ME. 2008. RNA editing of androgen receptor gene transcripts in prostate cancer cells. J Biol Chem 283: 29938-29949.

Mischo HE, Gómez-González B, Grzechnik P, Rondón AG, Wei W, Steinmetz L, Aguilera A, Proudfoot NJ. 2011. Yeast Sen1 helicase protects the genome from transcription-associated instability. Mol Cell 41: $21-32$.

Nagaraj N, Kulak NA, Cox J, Neuhauser N, Mayr K, Hoerning O, Vorm O, Mann M. 2012. System-wide perturbation analysis with nearly complete coverage of the yeast proteome by single-shot ultra HPLC runs on a bench top Orbitrap. Mol Cell Proteomics 11: M111.013722.

Niavarani A, Currie E, Reyal Y, Anjos-Afonso F, Horswell S, Griessinger E, Luis Sardina J, Bonnet D. 2015. APOBEC3A is implicated in a novel class of G-to-A mRNA editing in WT1 transcripts. PLoS One 10: e0120089.

Peng Z, Cheng Y, Tan BC, Kang L, Tian Z, Zhu Y, Zhang W, Liang Y, Hu X, Tan X, et al. 2012. Comprehensive analysis of RNA-Seq data reveals extensive RNA editing in a human transcriptome. Nat Biotechnol 30: 253-260.

Pickrell JK, Gilad Y, Pritchard JK. 2012. Comment on "Widespread RNA and DNA sequence differences in the human transcriptome". Science 335: 1302; author reply 1302

Rubio MA, Paris Z, Gaston KW, Fleming IMC, Sample P, Trotta CR, Alfonzo JD. 2013. Unusual noncanonical intron editing is important for tRNA splicing in Trypanosoma brucei. Mol Cell 52: 184-192.

Sharma PM, Bowman M, Madden SL, Rauscher FJ III, Sukumar S. 1994. RNA editing in the Wilms' tumor susceptibility gene, WT1. Genes Dev 8: $720-731$.

Shoichet BK, Baase WA, Kuroki R, Matthews BW. 1995. A relationship between protein stability and protein function. Proc Natl Acad Sci 92: $452-456$.

Silberberg G, Lundin D, Navon R, Öhman M. 2012. Deregulation of the Ato-I RNA editing mechanism in psychiatric disorders. Hum Mol Genet 21: 311-321. 
Skourti-Stathaki K, Proudfoot NJ, Gromak N. 2011. Human senataxin resolves RNA/DNA hybrids formed at transcriptional pause sites to promote Xrn2-dependent termination. Mol Cell 42: 794-805.

Sprague ER, Redd MJ, Johnson AD, Wolberger C. 2000. Structure of the Cterminal domain of Tup1, a corepressor of transcription in yeast. EMBO J 19: 3016-3027.

Stein H, Hausen P. 1969. Enzyme from calf thymus degrading the RNA moiety of DNA-RNA hybrids: effect on DNA-dependent RNA polymerase. Science 166: 393-395.

Tanaka N, Mukai Y. 2015. Yeast Cyc8p and Tup1p proteins function as coactivators for transcription of Stp1/2p-dependent amino acid transporter genes. Biochem Biophys Res Commun 468: 32-38.

Teng B, Burant CF, Davidson NO. 1993. Molecular cloning of an apolipoprotein B messenger RNA editing protein. Science 260: 1816-1819.

Tennyson GE, Sabatos CA, Higuchi K, Meglin N, Brewer HB. 1989. Expression of apolipoprotein B mRNAs encoding higher- and lower-molecular weight isoproteins in rat liver and intestine. Proc Natl Acad Sci 86: 500-504.

Trapnell C, Williams BA, Pertea G, Mortazavi A, Kwan G, van Baren MJ, Salzberg SL, Wold BJ, Pachter L. 2010. Transcript assembly and quantification by RNA-Seq reveals unannotated transcripts and isoform switching during cell differentiation. Nat Biotechnol 28: 511-515.

Tuduri S, Crabbé L, Conti C, Tourrière H, Holtgreve-Grez H, Jauch A, Pantesco V, De Vos J, Thomas A, Theillet C, et al. 2009. Topoisomerase I suppresses genomic instability by preventing interference between replication and transcription. Nat Cell Biol 11: 1315-1324.

Turner AJ, Aggarwal P, Miller HE, Waukau J, Routes JM, Broeckel U, Robinson RT. 2015. The introduction of RNA-DNA differences underlies interindividual variation in the human IL12RB1 mRNA repertoire. Proc Natl Acad Sci 112: 15414-15419.

Tyanova S, Mann M, Cox J. 2014. MaxQuant for in-depth analysis of large SILAC datasets. Methods Mol Biol 1188: 351-364.

van Dijk EL, Chen CL, d'Aubenton-Carafa Y, Gourvennec S, Kwapisz M, Roche V, Bertrand C, Silvain M, Legoix-Né P, Loeillet S, et al. 2011. XUTs are a class of Xrn1-sensitive antisense regulatory non-coding RNA in yeast. Nature 475: $114-117$.

van Leeuwen FW, de Kleijn DP, van den Hurk HH, Neubauer A, Sonnemans MA, Sluijs JA, Köycü S, Ramdjielal RD, Salehi A, Martens GJ, et al. 1998 Frameshift mutants of $\beta$ amyloid precursor protein and ubiquitin-B in Alzheimer's and Down patients. Science 279: 242-247.
Vazquez F, Ramaswamy S, Nakamura N, Sellers WR. 2000. Phosphorylation of the PTEN tail regulates protein stability and function. Mol Cell Biol 20: 5010-5018.

Vesely C, Tauber S, Sedlazeck FJ, von Haeseler A, Jantsch MF. 2012. Adenosine deaminases that act on RNA induce reproducible changes in abundance and sequence of embryonic miRNAs. Genome Res 22: 1468-1476.

Volchkov VE, Volchkova VA, Muhlberger E, Kolesnikova LV, Weik M, Dolnik O, Klenk HD. 2001. Recovery of infectious Ebola virus from complementary DNA: RNA editing of the GP gene and viral cytotoxicity. Science 291: 1965-1969.

Wang IX, So E, Devlin JL, Zhao Y, Wu M, Cheung VG. 2013. ADAR regulates RNA editing, transcript stability, and gene expression. Cell Rep 5: 849-860.

Wang IX, Core LJ, Kwak H, Brady L, Bruzel A, McDaniel L, Richards AL, Wu M, Grunseich C, Lis JT, et al. 2014. RNA-DNA differences are generated in human cells within seconds after RNA exits polymerase II. Cell Rep 6: 906-915.

Williams JS, Smith DJ, Marjavaara L, Lujan SA, Chabes A, Kunkel TA. 2013 Topoisomerase 1-mediated removal of ribonucleotides from nascent leading-strand DNA. Mol Cell 49: 1010-1015.

Worth CL, Preissner R, Blundell TL. 2011. SDM-a server for predicting effects of mutations on protein stability and malfunction. Nucleic Acids Res 39: W215-W222.

Wu HY, Burgess SM. 2006. Ndj1, a telomere-associated protein, promotes meiotic recombination in budding yeast. Mol Cell Biol 26: 3683-3694.

Wu TD, Nacu S. 2010. Fast and SNP-tolerant detection of complex variants and splicing in short reads. Bioinformatics 26: 873-881.

Wyers F, Sentenac A, Fromageot P. 1973. Role of DNA-RNA hybrids in eukaryotes. Ribonuclease H in yeast. Eur J Biochem 35: 270-281.

Zhang Y. 2008. I-TASSER server for protein 3D structure prediction. BMC Bioinformatics 9: 40 .

Zhang Z, Li C, Wu F, Ma R, Luan J, Yang F, Liu W, Wang L, Zhang S, Liu Y, et al. 2015. Genomic variations of the mevalonate pathway in porokeratosis. eLife 4: e06322.

Received April 2, 2016; accepted in revised form September 15, 2016.

\section{Genome Research}

www.genome.org 


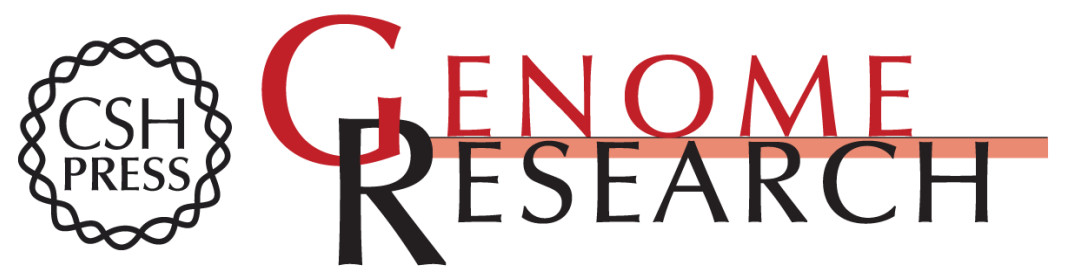

\section{RNA-DNA sequence differences in Saccharomyces cerevisiae}

Isabel X. Wang, Christopher Grunseich, Youree G. Chung, et al.

Genome Res. 2016 26: 1544-1554 originally published online September 16, 2016

Access the most recent version at doi:10.1101/gr.207878.116

Supplemental http://genome.cshlp.org/content/suppl/2016/10/17/gr.207878.116.DC1
Material

References This article cites 74 articles, 31 of which can be accessed free at: http://genome.cshlp.org/content/26/11/1544.full.html\#ref-list-1

Open Access Freely available online through the Genome Research Open Access option.

Creative This article, published in Genome Research, is available under a Creative

Commons Commons License (Attribution-NonCommercial 4.0 International), as described at

License http://creativecommons.org/licenses/by-nc/4.0/.

Email Alerting Receive free email alerts when new articles cite this article - sign up in the box at the Service top right corner of the article or click here.

\section{Affordable, Accurate Sequencing.}

To subscribe to Genome Research go to:

https://genome.cshlp.org/subscriptions

(C) 2016 Wang et al.; Published by Cold Spring Harbor Laboratory Press 